\title{
Histone demethylase LSD1 deficiency and biological sex: impact on blood pressure and aldosterone production
}

\author{
Yuefei Huanga, Pei Yee Tingb, Tham M Yaoa, Tsuyoshi Hommac, Danielle Brooksa, Isis Katayama Rangeld, \\ Gail K Adlera, Jose R Romeroa, Jonathan S Williamsa, Luminita H Pojogaa and Gordon H Williamsa
}

Division of Endocrinology, Diabetes and Hypertension, Department of Medicine, Brigham and Women's Hospital, Harvard Medical School, Boston, Massachusetts, USA

Correspondence should be addressed to L H Pojoga: Ipojoga@partners.org

a(Y Huang, T M Yao, D Brooks, G K Adler, J R Romero, J S Williams, L H Pojoga and G H Williams are now at Division of Endocrinology, Diabetes and Hypertension, Brigham and Women's Hospital, Boston, Massachusetts, USA)

b(P Y Ting is now at UCSI University, Kuala Terengganu Campus Bukit Khor, Mukim Rusila, Marang, Terengganu Darul Iman, Malaysia)

c(T Homma is now at Daiichi-Sankyo, Tokyo, Japan)

d(I K Rangel is now at Faculdade de Medicina da Universidade de São Paulo Av. Dr. Arnoldo, São Paulo - SP, Brazil)

\begin{abstract}
Human risk allele carriers of lysine-specific demethylase 1 (LSD1) and LSD1-deficient mice have salt-sensitive hypertension for unclear reasons. We hypothesized that LSD1 deficiency causes dysregulation of aldosterone's response to salt intake resulting in increased cardiovascular risk factors (blood pressure and microalbumin). Furthermore, we determined the effect of biological sex on these potential abnormalities. To test our hypotheses, LSD1 male and female heterozygote-knockout (LSD1+/-) and WT mice were assigned to two age groups: 18 weeks and 36 weeks. Plasma aldosterone levels and aldosterone production from zona glomerulosa cells studied ex vivo were greater in both male and female LSD1+/- mice consuming a liberal salt diet as compared to WT mice consuming the same diet. However, salt-sensitive blood pressure elevation and increased microalbuminuria were only observed in male LSD1+/- mice. These data suggest that LSD1 interacts with aldosterone's secretory response to salt intake. Lack of LSD1 causes inappropriate aldosterone production on a liberal salt diet; males appear to be more sensitive to this aldosterone increase as males, but not females, develop salt sensitivity of blood pressure and increased microalbuminuria. The mechanism responsible for the cardiovascular protective effect in females is uncertain but may be related to estrogen modulating the effect of mineralocorticoid receptor activation.
\end{abstract}

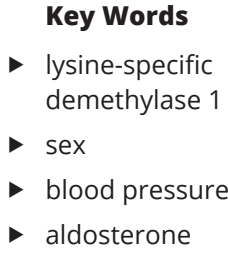

Journal of Endocrinology (2019) 240, 111-122

\section{Introduction}

Long-term uncontrolled high blood pressure results in left ventricular hypotrophy, kidney diseases and atherosclerosis (Ostchega et al. 2008). A major environmental contributor to the development of hypertension is liberal salt intake (Carvalho et al. 1989). A major regulator of sodium/volume homeostasis is aldosterone (Ehrhart-Bornstein et al. 1998, Lumbers 1999, Spat \& Hunyady 2004, Williams 2005). For more than a half-a-century, it has been known that aldosterone production, that is inappropriately elevated for the level of sodium intake, causes hypertension 
(Funder et al. 2008, Spyroglou et al. 2012). At first, the cause of the inappropriate aldosterone production was assumed to be secondary to an adrenal tumor. Later, it was documented that bilateral adrenal hyperplasia was associated with excess aldosterone production and hypertension. Recently, we have suggested that inappropriately increased aldosterone secretion may be present in a substantial fraction of both hypertensives and normotensives (Baudrand et al. 2017, Brown et al. 2017, Hundemer et al. 2018). The mechanisms that underlie the dysfunction in aldosterone secretion remain unclear.

Histone demethylase LSD1 (lysine-specific demethylase 1), also known as KDM1A, AOF2 and BHC110, is an epigenetic regulator (Shi et al. 2004). LSD1 specifically removes methyl groups from methylated lysine 4 (K4) and lysine 9 (K9) of histone 3 (H3) in a flavin adenine dinucleotide (FAD)-dependent oxidative reaction, resulting in dynamic transcriptional gene repression and activation (Shi et al. 2004, Metzger et al. 2005, Hamamoto et al. 2015). Also, LSD1 can demethylate lysine residues at non-histone proteins including p53, MYPT1, DNMT1 and E2F1 (Huang et al. 2007, Wang et al. 2009, Kontaki \& Talianidis 2010, Cho et al. 2011). Recently, we documented an association between LSD1, salt intake, aldosterone and hypertension. First, LSD1 levels are modified in response to changes in salt intake. Second, polymorphic variants of LSD1 gene in African descendants and Hispanics, but not Caucasians, are associated with salt-sensitive hypertension (SSH). The prevalence of the risk allele for hypertension is approximately $20 \%$. Third, male LSD1 heterozygous knockout (LSD1+/-) mice on liberal salt (LibS) diet have SSH associated with inappropriately increased aldosterone secretion (Pojoga et al. 2011, Williams et al. 2012, Krug et al. 2013, Baudrand et al. 2014). Thus, LSD1 variants may also be involved in the association between increased blood pressure and dysfunctional aldosterone secretion.

Biological sex has profound influence on aldosterone production and blood pressure. In a recent report from our group, females had higher aldosterone levels and greater salt-sensitive blood pressure than males. In premenopausal women plasma aldosterone levels are higher and the frequency of hypertension is lower than that in men, but after menopause, the difference in hypertension prevalence between men and women disappears (Yong et al. 1993, Himmelmann et al. 1994, Schunkert et al. 1997, Danser et al. 1998, Miller et al. 1999, Spyroglou et al. 2012). Also, it appears that estrogen protects against hypertension, while testosterone exacerbates hypertension (Reckelhoff 2001, Kang \& Miller 2002, Sandberg \& Ji 2003). In contradiction is the observation that giving estrogen to postmenopausal women increases cardiovascular risk. Furthermore, in rodents on a LibS diet, estrogen can have adverse cardiovascular effects (Stier et al. 2003, Oestreicher et al. 2006). Thus, estrogen has controversial effects on the cardiovascular system and an unclear relationship with aldosterone. While there is a clear relationship between androgens and LSD1, there is less information concerning a relationship between LSD1 and estrogen (Garcia-Bassets et al. 2007, Bennesch et al. 2016).

Based on these data, we posit that LSD1 deficiency causes dysregulation of the aldosterone response to salt intake with a resulting increase in blood pressure in a sex-specific manner. To test this hypothesis, we took advantage of our LSD1+/- mouse model and our wellestablished, acutely isolated glomerulosa cell preparation.

\section{Materials and methods}

\section{Animals}

In a longitudinal study of estrous cyclicity in aging C57BL/6J mice, three phases were defined for the life of female mice: phase I with initial prolonged cycles and latestarting cyclers until mice are 12-15 weeks of age, phase II up to 44-64 weeks of age and cycle frequency declined steadily in phase III (>64 weeks of age) (Nelson et al. 1982, Felicio et al. 1984). We studied 18- and 36-week-old female mice as representatives for the first two phases of the young female mouse's life because they had relatively high plasma estradiol levels. Correspondingly, we studied 18and 36-week-old male mice for sex comparison. Because of the findings in the female mice, we also assessed blood pressure levels in 52-week-old female mice.

LSD1+/- mice were generated by gene trap with C57BL/6J background, as we previously reported (Williams et al. 2012). At 12-13 weeks of age, female and male mice were randomly assigned to two cohorts, each comprising 40-50 animals. One cohort was studied at age 18 weeks and the other at 36 weeks. Each cohort consisted of LSD1+/and WT litter mates. The mice were kept on LibS diet ( $4 \% \mathrm{NaCl}$ Purina Chow), except for 1 -week of restricted salt diet $(0.05 \% \mathrm{NaCl}$ Purina Chow) to measure their systolic blood pressure on restricted salt (ResS) diet wwcondition. We also conducted monthly metabolic assessments, by housing individual mice in metabolic cages for $24 \mathrm{~h}$. The 24-h data on food intake, water intake and urine volume were not significant different between genotypes for each sex. All animal procedures were approved by the 
Institutional Animal Care and Use Committee at Brigham and Women's Hospital.

\section{Blood pressure measurement}

Blood pressure measurement was performed as previously reported by us (Pojoga et al. 2010, Chuengsamarn et al. 2013). Systolic blood pressure (SBP) was assessed by tailcuff plethysmography (CODA tail-cuff blood pressure system, Kent Scientific Corporation, Torrington, CT, USA). All measurements were taken in the morning after 1 week of training. Values from 30 to 40 measurement cycles were used to calculate average SBP and standard deviation (s.D.) for each mouse. Any readings greater than two S.D. from the mean were excluded. The final mean value of SBP for each cohort was calculated from average SBPs of individual mice and is presented as mean \pm s.E.m. Delta SBP $(\triangle \mathrm{SBP})$ was calculated as SBP on the LibS diet minus SBP on the ResS diet. The final mean value of $\triangle S B P$ for each cohort was calculated from $\triangle \mathrm{SBP}$ for individual mice and is presented as mean \pm S.E.M.

\section{Tissue preparation}

On the last day of the study, mice were anesthetized by isoflurane (Sigma-Aldrich) and blood was collected from the facial vein. The left ventricle of the heart and adrenal glands were rapidly excised, weighed, dissected, frozen in liquid nitrogen and stored at $-80^{\circ} \mathrm{C}$.

\section{Plasma aldosterone and corticosterone measurements}

Blood was collected in BD Microtainer tubes with EDTA. The plasma was separated by centrifugation. Plasma aldosterone levels were measured using an aldosterone ELISA kit (IBL International GMBH, Hamburg, Germany) and plasma corticosterone levels were measured using a corticosterone ELISA kit (Enzo Life Sciences Inc., Farmingdale, NY, USA).

\section{Ex vivo aldosterone secretion and response assay}

At the time of killing, most of the adrenal glands were collected fresh for preparation of a purified, isolated glomerulosa cell preparation as previously reported by us (Braley et al. 1981, 1996, Baudrand et al. 2015, Garza et al. 2015, Chong et al. 2017). In brief, adrenals were bisected and by blunt scraping the zona glomerulosa (ZG) capsular layer was separated from the fasciculata/medulla.
The capsules were suspended in Krebs Ringer bicarbonate solution (Sigma-Aldrich) (0.1\% BSA, $200 \mathrm{mg}$ glucose/dl, L-glutamine, $3.7 \mathrm{mmol} / \mathrm{L}$ of $\mathrm{K}^{+}$) (KRBGA) solution with collagenase $(3.7 \mathrm{mg} / \mathrm{mL})$ and DNAase $(0.05 \mathrm{mg} / \mathrm{mL})$ (Worthington Biochemical, Freehold, NJ, USA) for 60-min incubation at $37^{\circ} \mathrm{C}$ under $95 \% \mathrm{O}_{2}$ and $5 \% \mathrm{CO}_{2}$. Isolated ZG cells underwent three rounds of brief washing and centrifugation followed by determination of cell count. Purity of the preparation was determined as previously described (Braley et al. 1981, 1996).

Equal amounts of cells $(\sim 50,000)$ were incubated with $10^{-7} \mathrm{M}$ angiotensin II (ANGII) or $8.7 \mathrm{mM}$ potassium $\left(\mathrm{K}^{+}\right)$ for $60 \mathrm{~min}$ at $37^{\circ} \mathrm{C}$ under $95 \% \mathrm{O}_{2}$ and $5 \% \mathrm{CO}_{2}$. Basal as well as ANGII and $\mathrm{K}^{+}$-stimulated aldosterone secretion levels were determined, and the aldosterone levels normalized to 1 million cells.

\section{Urine microalbumin}

Three days prior to killing, mice were placed in metabolic cages to collect $24-\mathrm{h}$ urines. Urine microalbumin was measured using DCA 2000 microalbumin reagent kit (Bayer, Elkhart, IN, USA). The detectable range was $5-300 \mu \mathrm{g} / \mathrm{mL}$. The inter-assay CVs were $<5 \%$. For statistical purposes, an undetectable microalbumin was assigned a value of $2 \mu \mathrm{g} / \mathrm{mL}$. A $24-\mathrm{h}$ urine albumin excretion rate (24-h UAE) was calculated using the formula: urine microalbumin $(\mu \mathrm{g} / \mathrm{mL}) \times 24$ - $\mathrm{h}$ urine volume $(\mathrm{mL})=24-\mathrm{h}$ UAE $(\mu \mathrm{g} / 24 \mathrm{~h})$. The results from both the 18 and 36 weeks were combined.

\section{Real time RT-PCR}

Real time RT-PCR was performed as previous reported by us (Pojoga et al. 2011, 2014). In brief, total mRNA was extracted using RNeasy kit (Qiagen Sciences) and reverse transcribed using the first-strand cDNA synthesis kit (GE Healthcare, Piscataway, NJ, USA). Amplification was performed with TaqMan gene expression assays, using the $\Delta \Delta \mathrm{Ct}$ method. Data were normalized to $18 \mathrm{~S}$ rRNA. Data are presented as fold change relative to the measurement in 18-week WT mice.

\section{Electrophoresis and Western blots}

Electrophoresis and Western blots were performed as previous reported by us (Pojoga et al. 2011, 2015). In brief, homogenates of mouse hearts were size-fractionated by electrophoresis on 10\% SDS-PAGE gels. Proteins were then transferred onto nitrocellulose membrane. 
The membranes were first blocked with $5 \%$ milk for $1 \mathrm{~h}$ at room temperature, and then incubated overnight at $4^{\circ} \mathrm{C}$ with the primary antibodies - rabbit anti-MR (1:500, Santa Cruz), washed, incubated with peroxidaseconjugated secondary antibody and analyzed by enhanced chemiluminescence (Denville scientific Inc., Holliston, MA, USA). To correct for loading, blots were re-probed with mouse anti- $\beta$-tubulin (1:6000, Sigma-Aldrich). Data are presented as fold change relative to the measurement in WT mice.

\section{Statistical analysis}

The statistical significance of difference between groups was determined either by unpaired $t$-test (two-tailed) or by Fisher's exact test (for limited sample size). Significance of differences of paired variables (i.e. salt sensitivity induced by different salt intakes) was tested by paired $t$-test. Calculated $P$ values less than or equal to 0.05 were considered statistically significant except for those analyses with multiple comparisons where the $P$ value was adjusted to 0.025. Mean values are presented as mean \pm S.E.M.

\section{Results}

\section{LSD1 mRNA was significantly decreased in LSD1+/- mice}

To confirm LSD1+/- mice had decreased LSD1 expression, we analyzed LSD1 mRNA expression levels (RT-qPCR) in hearts of four randomly picked LSD1+/- and WT mice from each cohort of both sexes and compared the values in the LSD1+/- with WT mice by fold change. Both male and female LSD1+/- mice had significantly decreased LSD1 mRNA levels compared to WT (Fig. 1).

\section{Male LSD1+/- mice, but not females, had elevated SBP on a LibS diet}

To test whether LSD1 deficiency caused an increase in blood pressure in young LSD1+/- mice on LibS diet, we measured SBP. Male LSD1+/- mice had significantly higher SBP compared to WT mice at both 18 weeks (LSD1+/- $142.7 \pm 2.3 \mathrm{mmHg}$ vs WT $118.4 \pm 1.4 \mathrm{mmHg}$, $P<0.0001$ ) and 36 weeks (LSD1+/- $121.0 \pm 3.6 \mathrm{mmHg}$ vs WT $108.4 \pm 2.9 \mathrm{mmHg}, P<0.05$ ) of age (Fig. 2A), consistent with our previous reports (Krug et al. 2013). However, we did not observe an increase of SBP in female
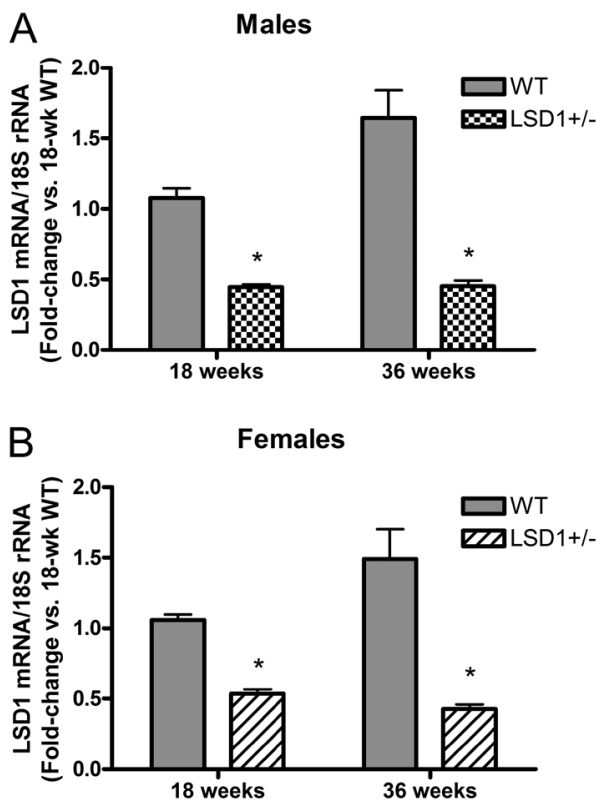

Figure 1

RT-PCR of lysine-specific demethylase-1 (LSD1) mRNA expression in heart tissues from male (A) and female (B) mice. Data represent mean \pm s.E.M. $(n=4)$. Statistical analyses were conducted using unpaired $t$-test (two-tailed). ${ }^{*} P<0.001$ vs same-age WT.

LSD1+/-miceateither18weeks(LSD1+/-117.9 $\pm 3.1 \mathrm{mmHg}$ vs WT $119.3 \pm 3.2 \mathrm{mmHg}, P=0.76$ ) or 36 weeks (LSD1+/$121.0 \pm 2.4 \mathrm{mmHg}$ vs WT $116.9 \pm 2.2 \mathrm{mmHg}, \quad P=0.21)$ of age (Fig. 2B). As expected, SBP variation was driven by a significant age-genotype interaction in the males $(P<0.05)$, but not in the females $(P=0.31)$. The failure to increase blood pressure persisted even in 52-week-old female mice (LSD1+/- $125.5 \pm 2.2 \mathrm{mmHg}, n=10$ and WT $123.4 \pm 2.9 \mathrm{mmHg}, n=10$ ). The data in the male mice are consistent with what we observed in aged male mice and individuals of African descent (Pojoga et al. 2011, Williams et al. 2012, Krug et al. 2013). However, compared to age-matched male LSD1+/- mice, female LSD1+/- mice did not have an increased SBP; consistently, there was a significant interaction between age and gender for the SBP in the LSD1+/- mice $(P<0.001)$.

\section{LSD1 deficiency affected salt sensitivity of blood pressure in males but not in females}

We examined the $\triangle$ SBP (SBP on LibS minus SBP on low salt) in our mice. (Franco \& Oparil 2006, Rodriguez-Iturbe $\&$ Vaziri 2007). While male WT mice showed no significant $\triangle \mathrm{SBP}(-2.3 \pm 1.5 \mathrm{mmHg}$ at 18 weeks and $8.3 \pm 7.0 \mathrm{mmHg}$ at 36 weeks), male LSD1+/- mice exhibited a highly significantly increased $\Delta$ SBP $(25.1 \pm 2.7 \mathrm{mmHg}$ at 18 weeks 

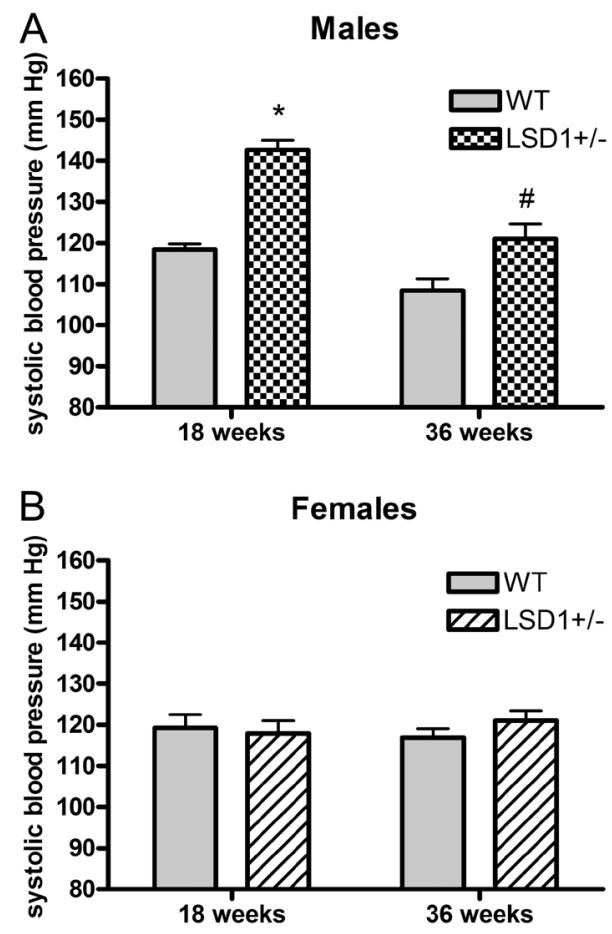

Figure 2

Systolic blood pressure (SBP) in male (A) and female (B) mice on a liberal salt diet. Data represent mean \pm S.E.M. (sample sizes per genotype group: 18 week males: $20-21 ; 36$ week males: 11-13; 18 week females: 21-27; 36 week females: $25-29)$. Statistical analyses were conducted using unpaired $t$-test (two-tailed). ${ }^{*} P<0.00001 ;{ }^{*} P<0.05$ vs same-age WT.

and $19.2 \pm 4.6 \mathrm{mmHg}$ at 36 weeks, $P<0.00001$ and $P<0.01)$ (Table 1). In contrast, in females, LSD1+/- mice exhibited no significant change in $\triangle \mathrm{SBP}$ and the WT females only had a small change at 36 weeks, but it was in the negative direction (Table 1).

\section{LSD1 deficiency caused excessive aldosterone production on LibS diet in both male and female mice}

Under normal physiological conditions consuming a LibS diet, as compared to a ResS diet, results in a decrease in aldosterone production and a blunted aldosterone rise in response to the aldosterone secretagogues angiotensin II (ANGII) and $\mathrm{K}^{+}$both in vivo and ex vivo in studies of isolated rodent zona glomerulosa (ZG) cells (Williams \& Hollenberg 1991). To determine if the increased $\triangle S B P$ observed in LSD1+/- mice is secondary to inappropriately increased aldosterone secretion on a LibS diet, we examined aldosterone secretion ex vivo in ZG cells. As early as 18 weeks of age, the ZG cells from male LSD1+/- mice, as compared to male WT mice, had significantly higher aldosterone levels, basally, $(P<0.001)$ and in response to ANGII $(P<0.00001)$ and $\mathrm{K}^{+}(P<0.00001)$ stimulation (Fig. 3A). However, this phenotype disappeared by age 36 weeks. In ZG from female LSD1+/- mice at 18 weeks, the aldosterone response only to $\mathrm{K}^{+}$was significantly increased compared to female WT mice. At 36 weeks, ZG secretion of aldosterone, basally, and in response to ANGII and $\mathrm{K}^{+}$were significantly increased compared to female WT (Fig. 3B). Collectively, these ex vivo data strongly suggest that LSD1 deficiency contributes to abnormally high aldosterone production on LibS diet for both sexes.

\section{Both male and female LSD1+/- mice had elevated circulating aldosterone levels on LibS diet}

Consistent with what we observed ex vivo, male LSD1+/mice had significantly higher plasma aldosterone levels than WT $(389.0 \pm 24.8$ vs $303.9 \pm 63.8 \mathrm{pg} / \mathrm{ml}, P=0.05)$ at the age of 18 weeks, while female LSD1+/- mice had significantly higher plasma aldosterone levels than WT $(329.1 \pm 45.2$ vs $200.0 \pm 13.4 \mathrm{pg} / \mathrm{ml}, P<0.05)$ at the age of 36 weeks (Fig. 4A and B). Thus, the changes in the plasma aldosterone levels mimic what was observed ex vivo. As a control for the effects of stress and/or adrenocorticotropic hormone (ACTH), we measured plasma corticosterone levels. There were no significant differences in corticosterone levels between genotypes or ages in either male or female mice (Fig. 4C and D).

Table 1 Delta systolic blood pressure $(\triangle \mathrm{SBP})$ in male and female mice.

\begin{tabular}{|c|c|c|c|c|c|c|c|c|}
\hline \multirow{2}{*}{ Sex } & \multicolumn{4}{|c|}{ Males } & \multicolumn{4}{|c|}{ Females } \\
\hline & 18-weeks WT & 18-weeks HET & 36-weeks WT & 36-weeks HET & 18-weeks WT & 18-weeks HET & 36-weeks WT & 36-weeks HET \\
\hline$\triangle \mathrm{SBP}(\mathrm{mmHg})$ & $-2.3 \pm 1.5$ & $25.1 \pm 2.7$ & $8.3 \pm 7.0$ & $19.2 \pm 4.6$ & $5.8 \pm 4.1$ & $-3.7 \pm 4.8$ & $-6.9 \pm 3.1$ & $-3.0 \pm 4.8$ \\
\hline Sample size $(n)$ & 18 & 21 & 12 & 11 & 21 & 27 & 29 & 25 \\
\hline $\begin{array}{l}P \text { value (Paired } \\
t \text {-test) }\end{array}$ & 0.31 & $P<0.00001$ & 0.26 & 0.002 & 0.17 & 0.45 & 0.03 & 0.53 \\
\hline $\begin{array}{l}P \text { value (WT vs HET, } \\
\text { unpaired } t \text {-test) }\end{array}$ & & $P<0.00001$ & & 0.21 & & 0.14 & & 0.5 \\
\hline
\end{tabular}

$\triangle$ SBP was calculated as systolic blood pressure on a liberal salt diet minus systolic blood pressure on a restricted salt diet. Data represent mean \pm S.E.M. Paired $t$-test (two-tailed) was used to assess the statistical significance of the $\Delta$ SBP individually within each of the eight cohorts. Unpaired $t$-test (two-tailed) was used to compare values of $\triangle$ SBP between WT and HET of the same sex and age. 

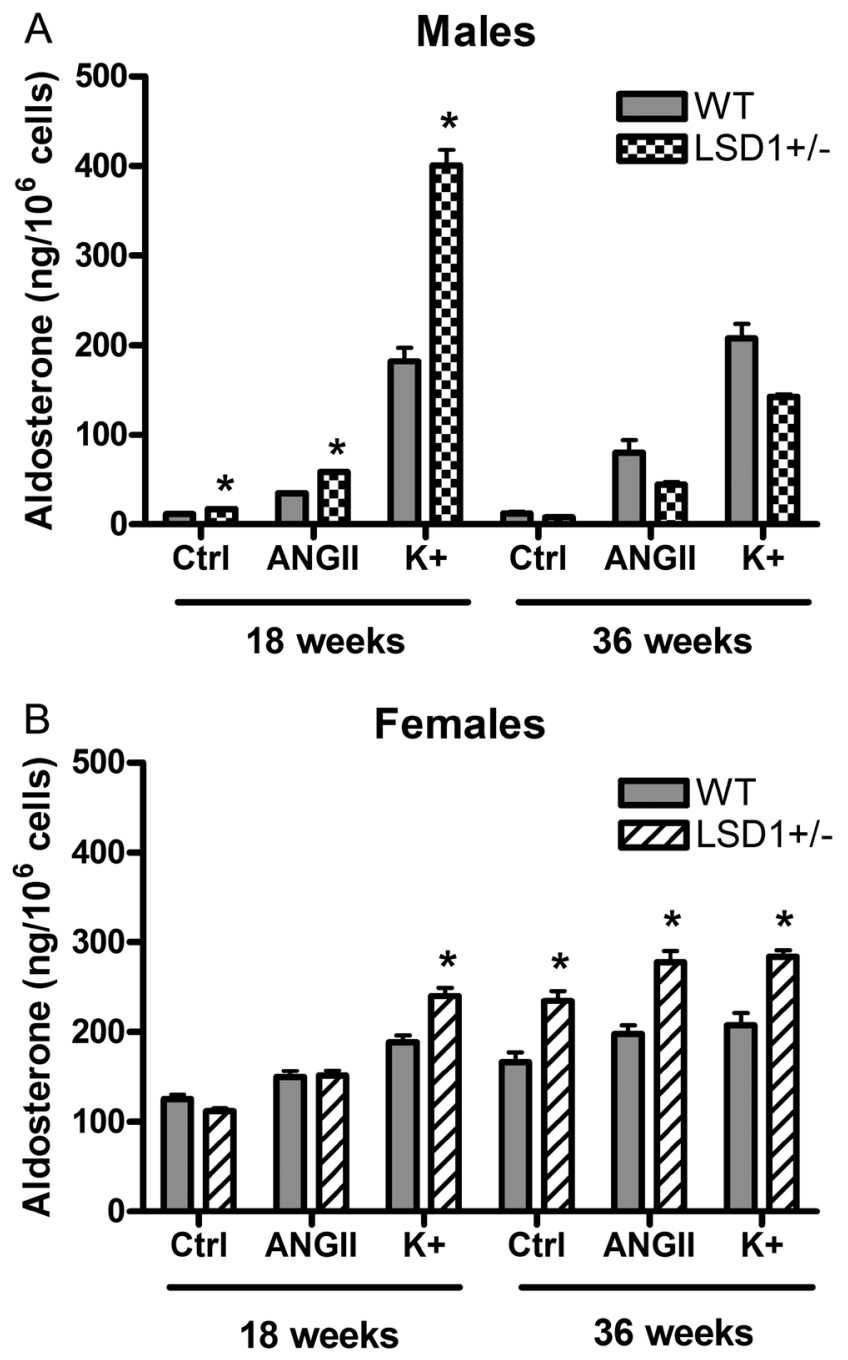

Figure 3

Ex vivo aldosterone secretion and response to secretagogues (ANGII, $10^{-7} \mathrm{M}$ and $\mathrm{K}^{+}, 8.7 \mathrm{mM}$ ) in adrenal $\mathrm{ZG}$ cells from male $(\mathrm{A})$ and female (B) mice consuming a liberal salt diet. Data represent mean \pm S.E.M. Sample size is $3-4 /$ condition for males and 6-10/condition for females. ${ }^{*} P<0.05$ vs corresponding measurements in WT.

On LibS diet, male LSD1+/- mice had significantly higher 24-h urine microalbumin excretion rates than female LSD1+/- mice

Renal dysfunction on a LibS diet was assessed by measuring 24-h microalbuminuria. Male LSD1+/- mice had significantly higher 24-h microalbuminuria than female LSD1+/- mice $(19.9 \pm 2.5$ vs $6.9 \pm 1.3 \mu \mathrm{g} / 24 \mathrm{~h}, \quad P<0.001)$ regardless of age 18 or 36 weeks. Additionally, male WT mice also had significantly greater microalbuminuria than WT female mice $(14.7 \pm 2.7$ vs $7.2 \pm 0.5 \mu \mathrm{g} / 24 \mathrm{~h}, P<0.05)$, suggesting that in LSD1+/- mice, males may be more vulnerable than females to the renal injury induced by a LibS intake in the presence of excessive aldosterone secretion.
Decreased cardiac mineralocorticoid receptor (MR) protein levels were associated with elevated circulating aldosterone levels

Restricting salt intake, which increases circulating levels of aldosterone, is associated with decreased MR protein level in cardiac tissue likely through a negative feedback mechanism (Ricchiuti et al. 2011). Cardiac levels of MR protein were significantly decreased in 18-week-old male LSD $1+/-$ vs WT mice $(0.3 \pm 0.02$ vs $1.0 \pm 0.2, P<0.05)$ (Fig. 5A), while it was in the 36-week-old females that the levels tended to decrease $(1.1 \pm 0.1$ vs $1.6 \pm 0.4, P=0.09)$ (Fig. 5B). These are also the ages in the two sexes when aldosterone levels were significantly increased. In contrast, in each sex when aldosterone levels did not differ between WT and LSD1+/- mice, MR protein levels in the heart also did not differ (36 weeks in males and 18 weeks in females). These results suggest that the changes in the circulating aldosterone levels led to the changes in the cardiac MR protein levels, supporting the functional effects of the increased aldosterone in male LSD1+/- mice.

\section{Discussion}

We hypothesized that a decrease in LSD1 causes dysregulation of the aldosterone response to increases in dietary salt intake with a resulting increase in blood pressure and these responses are modified by sex. Our results support this posit. First, in both male and female LSD1+/- mice, aldosterone production and circulating levels were inappropriately increased on a LibS intake compared to WT mice. It would be assumed that the increased aldosterone would result in an increase in blood pressure on the LibS diet, and indeed it did in the male mice. In contrast to male WT mice, male LSD1+/- mice had $15-20 \mathrm{mmHg}$ higher SBPs on the LibS diet. This increase in SBP was present as early as 18 weeks of age and persisted to at least 36 weeks of age, even though aldosterone levels were decreasing toward the 'normal' WT values by 36 weeks. However, the blood pressure in female LSD1+/- and WT mice did not differ at either age, even though the aldosterone levels of 36-week-old female LSD1+/- mice was clearly increased. Furthermore, even 4 months later, the blood pressures of 52-week female LSD1+/- mice were not increased. Not only was blood pressure increased in male vs female LSD1+/- mice, but also male LSD1+/- mice had more microalbuminuria than females. These sex differences were not secondary to the differences of LSD1 levels, as the reduction of LSD1 mRNA levels were similar in LSD1+/- mice of both sexes; 

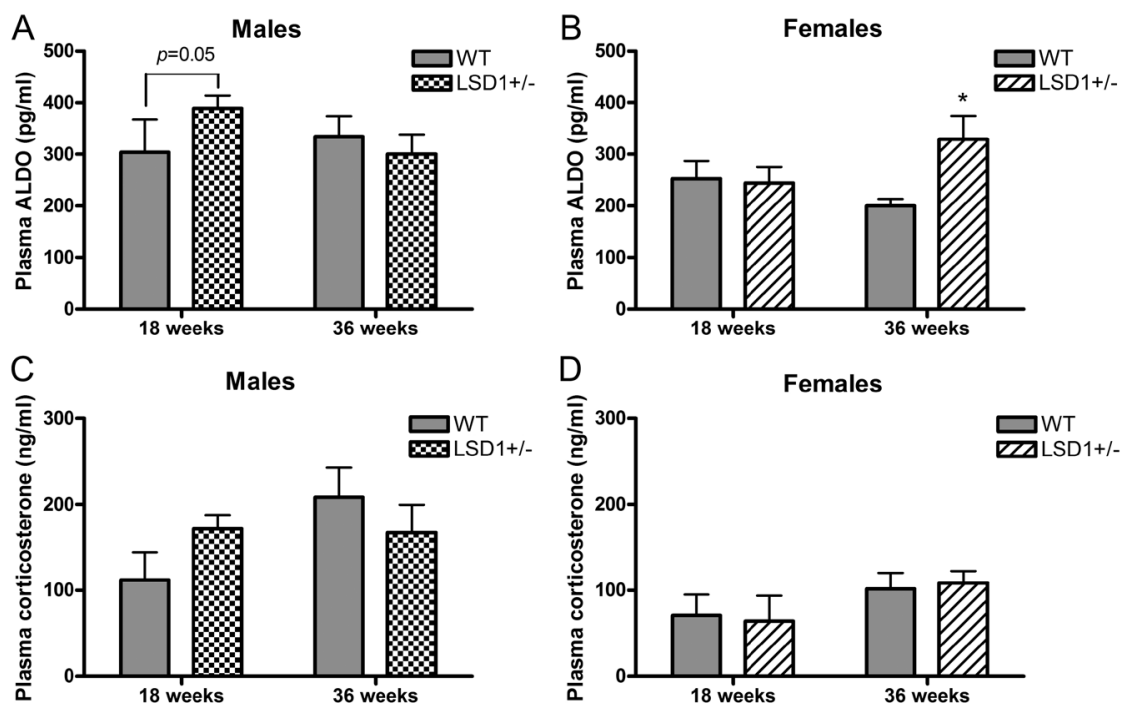

\section{Figure 4}

Plasma aldosterone and corticosterone levels in male ( $A$ and $C$ ) and female ( $B$ and $D$ ) mice consuming a liberal salt diet. Data represent mean \pm S.E.M. Sample sizes for ALDO (corticosterone) per genotype group were: 18 week males: 9 (6); 36 week males: 17-19 (6); 18 week females: 9-10 (6); 36 week females: 12-14 (13-14). Statistical analyses were conducted using unpaired $t$-test (two-tailed), except for the data in panel A), where the Fisher's exact test was used. $* P<0.05$ vs same-age WT. nor to the ability of aldosterone to modulate MR levels, as the decreases in cardiac MR were associated with the increases in aldosterone levels for both sexes. Thus, we conclude that the sex-specific, SSH associated with LSD1 deficiency in male rodents is secondary to an impaired ability to reduce aldosterone secretion in response to a LibS intake. In female LSD1+/-, the hormonal phenotype is present, but it does not result in the vascular one.

It has been postulated that hypertension is a multifactorial condition determined by sex, genes, diet, age, environment and their metabolic interactions (Simon et al. 2016). This postulate suggests that hypertension is not a disease but a syndrome: a collection of diseases all of which have a common sign - a blood pressure high enough to be considered elevated. Several approaches have been used to identify the individual diseases that underlie the hypertension syndrome. One has been genetic with polymorphic variants of a gene being the biomarker for a specific hypertension disease. LSD1 is one of these candidate genes. LSD1 is a histone demethylase that functions as an epigenetic modulator to selectively remove mono- and dimethyl groups from lysine 4 or lysine 9 of histone 3, thereby causing either suppression or activation of gene transcription. We previously documented that salt intake modifies the level of LSD1 in WT mice (Williams et al. 2012) and reported that LSD1 deficiency is associated with SSH, enhanced vascular contraction and reduced vascular relaxation in aged male mice. Specifically, compared to WT, aged male LSD1+/mice had significantly: (1) enhanced phenylephrine concentration-dependent aortic contraction and (2) reduced acetylcholine concentration-dependent relaxation in aortic segments pre-contracted with phenylephrine (Pojoga et al. 2011). Moreover, our clinical study also identified two LSD1 SNPs that are significantly associated with salt-sensitive blood pressure in individuals of African descent $(P<0.01 ; P<0.05)$ (Williams et al. 2012). Thus, both experimental and clinical data suggest that LSD1 is an important epigenetic regulator of blood
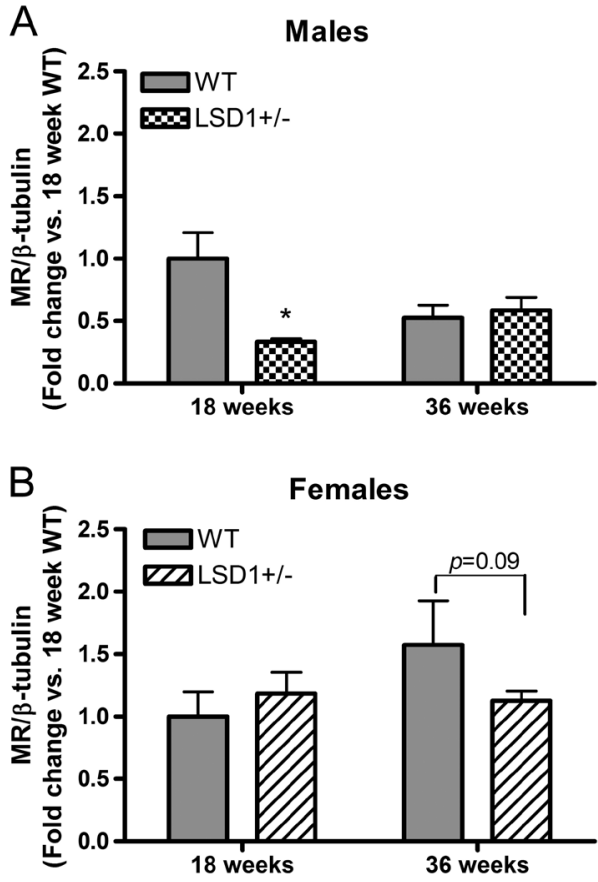

Figure 5

Cardiac MR protein levels relative to $\beta$-tubulin in male (A) and female (B) mice. Data represent mean \pm S.E.M. $(n=6 /$ group). Statistical analyses were conducted using unpaired $t$-test (two-tailed) for (A) and Fisher's exact test for (B). Gels for MR and $\beta$-tubulin immunoreactive bands are presented at the bottom of corresponding graphs. $* P<0.01$ vs same-age WT. 
pressure, which provides a potential link between salt intake and the development of SSH.

In several hypertensive rat models (spontaneously hypertensive, Dahl salt-sensitive and deoxycorticosterone salt), the SSH is linked to abnormalities in secretion of mineralocorticoids (Gomez-Sanchez et al. 2010, Watson et al. 2013). Thus, we assessed whether LSD1 deficiency also could result in dysregulated aldosterone secretion and thereby be a mediator of the SSH with LSD1 deficiency. Perhaps it is not surprising, given the genetic basis of the hypertension in this model, that the likely mechanism inappropriately increased aldosterone levels on a LibS diet was present from an early age. Aldosterone's dysregulation was documented in vivo and ex vivo in isolated glomerulosa cells, suggesting that the dysregulation is occurring at the level of the glomerulosa cell itself rather than being secondary to abnormalities in one or more aldosterone signaling pathways or negative feedback loops. This posit is further supported by the normal regulation of the MR by aldosterone: as aldosterone levels increased, cardiac MR levels were reduced. Thus, the increased aldosterone production in LSD1+/- mice suggests that LSD1 inhibits aldosterone secretion on a LibS diet and/or is involved in the change of aldosterone production when dietary salt intake is shifted from low to high. Aldosterone secretion is mainly regulated by the activity of two enzymes in its biosynthetic pathway-aldosterone synthase (CYP11B2) and cholesterol side chain cleavage enzyme (CYP17A1). CYP11B2 is more involved in modifying aldosterone secretion in response to changes in salt and $\mathrm{K}^{+}$intake. However, it is unclear where LSD1 interacts in the aldosterone biosynthetic pathway, i.e. CYP17A1 and/or CYP11B2, or how, i.e. directly or indirectly. Above all, except for some differences in the age of onset of the altered aldosterone secretion, LSD1 deficiency in both sexes showed the same aldosterone effect.

Sexual dimorphism has been documented previously for blood pressure levels and regulation (Yong et al. 1993, Himmelmann et al. 1994). In humans, hypertension is more common in young males than in premenopausal females; the difference disappears following menopause (Coylewright et al. 2008, Reckelhoff \& Maric 2010). In rodent models of hypertension (spontaneously hypertensive, Dahl salt-sensitive and deoxycorticosterone salt hypertensive), males have higher blood pressure than age-matched females although both sexes are hypertensive (Ouchi et al. 1987, Karatas et al. 2008, Bubb et al. 2012). LSD1 deficiency is also associated with sexual dimorphism, even more extreme than what has been previously reported in rodent models of hypertension, when the levels of the presumed mediators are the same in males and females. One could reason that interaction with age is required to produce the hypertension. However, this possibility seems unlikely, since the blood pressure in 52-week-old female LSD1+/- mice was still substantially lower than that of 18-week-old male LSD1+/- mice.

What could explain this sex difference? Several mechanisms may be involved. First, we recently documented that estradiol (E2)-activated estrogen receptor alpha (ER $\alpha)$ inhibits MR-mediated gene transcription, but the reverse does not occur (Barrett Mueller et al. 2014). Specifically, ER $\alpha$ and the MR are part of a complex in cell lysates. ERo's ability to enter the nucleus and complex with MR correlates with its ability to inhibit MR-mediated gene transcriptional activity. Second, there are controversial reports concerning the relationship between biological sex and circulating aldosterone levels. Manrique et al reported female C57BL6/J fed with either a control diet or a western diet had significantly higher plasma aldosterone levels than males (Manrique et al. 2013). In clinical studies, Miller et al reported plasma aldosterone levels were lower in women than men with equivalent salt intake (Miller et al. 1999), while women from Framingham Offspring Study showed higher circulating aldosterone levels than men (Kathiresan et al. 2005). Katz et al reported that with salt restriction, plasma aldosterone were higher in women than in men (Katz et al. 1972). We recently reported, in a large cohort, that women vs men had more salt-sensitive blood pressure and greater vascular and aldosterone response to ANGII. This study also documented that female vs male rats had higher aldosterone excretion rates and response to ANGII stimulation both ex vivo and in vivo. Female rats also had greater cardiac and renal dysfunction in a rat model of cardiovascular damage that was largely prevented by administration of a MR antagonist (Shukri et al. 2018). Because aldosterone production and circulating aldosterone level are delicately regulated by salt intake, these discrepancies in the literature are likely secondary to lack of control for environmental factors, especially salt intake or sample size. Yet, regardless of the facts that female and male LSD1+/- mice have the same increased aldosterone phenotype and other studies have reported that female rats will have more aldosteronemediated cardiovascular damage, which is not the case with LSD1+/- mice.

Microalbuminuria is one of the earliest indications of renal injury in both diabetic and non-diabetic subjects and is associated with high incidence of cardiovascular morbidity (Abbate et al. 1999, Rayner 2006, Schrader et al. 2006, Barratt \& Topham 2007). 
Furthermore, aldosterone is a potent effector of renal injury (Epstein 2001, Hostetter \& Ibrahim 2003, Hollenberg 2004) with some studies documenting a strong correlation between aldosterone levels and the degree of proteinuria (Baldoncini et al. 1999, Sato et al. 2003, Nitta et al. 2004, Bianchi et al. 2005). Experimental data also indicate that the adverse cardiorenal effects of aldosterone excess are dependent on concomitant high salt intake (Pimenta et al. 2008). Thus, aldosterone excess and high dietary salt combine to increase urinary protein excretion and accelerate renal impairment, though the pathological processes by which this occurs are uncertain (Hollenberg 2004). But in our study, excessive aldosterone production and high-salt diet did not result in significant higher 24-h urinary albumin excretion in either male or female LSD1+/- mice. However, we observed, on a LibS diet, male mice had significantly higher 24-h urinary albumin excretion than females. Our observation of the sex differences in 24-h urinary albumin excretion is consistent with a study in aged stroke-prone spontaneously hypertensive rats (SHRSP): male SHRSP exhibited greater proteinuria than females. (Masineni et al. 2005). It is consistent also with a study in non-diabetic, British, Caucasian subjects aged 40-75 years, which reported that mean albumin excretion rates were significantly higher in men than women (Gould et al. 1993).

What are the clinical implications of our findings? Our study demonstrated LSD1 functions as an epigenetic modulator of aldosterone production for both sexes and plays roles in regulating blood pressure. These results are in line with the theory that impaired LSD1 activity/ expression results in an uncoupling of the normal saltregulated control over aldosterone production and vasculature function (Pojoga et al. 2011). In clinic, these findings will allow us to identify individuals with $L S D 1$ risk alleles and to specifically treat them with MR antagonists as a preventive or therapeutic modality. This mechanismdriven, precision approach, rather than a non-specific treatment of hypertension, will be groundbreaking in treating those with and/or at risk of SSH. However, it is important to emphasize the sex differences identified in this study relative to the mechanisms underlying the development of SSH and cardiovascular diseases. The results from our study raise a caution concerning extrapolation of mechanisms underlying $\mathrm{SSH}$ in males to females. The female mice appeared to have the same potential pathophysiological defect that could lead to SSH as the male mice, but SSH was not evident. Therefore, it is necessary to create more specific guidelines allowing clinicians to stratify risk for sex and to better tailor care to men and women.

There are several limitations to our study. (1) Rodents have a short reproductive cycle. During the $4-5$ days of estrous cycle, plasma concentration of estrogen change (Nelson et al. 1982, Felicio et al. 1984). It is well known that BP varies with estrogen levels. We did not synchronize the estrous cycle of studied female mice or conduct ovariectomy and estrogen replacement experiments to exclude the effect of variable estrogen levels on blood pressure readings. (2) Sex-related differences include not only the action of gonadal steroids, but also chromosomal sex. The present study did not consider the effect of chromosomal sex. (3) Aging also has profound influences on BP and aldosterone production. We had only a limited assessment of aging on our findings. (4) We did not perform an ablation experiment in the males to determine if, indeed, aldosterone was the driver of the $\mathrm{BP}$ response to salt intake. (5) Approaches to determine sample size adequacy vary considerably by type and purpose of analysis. Thus, the relatively small sample size for some of our outcomes may reduce the statistical power. However, with our sample size, we did see a sex-specific effect of lower LSD1 levels on BP, but no sex-specific effects on aldosterone secretion. In both males and females, aldosterone secretion was abnormal. (6) Though non-invasive, tailcuff blood pressure measurement is commonly used for mutagenesis or genetic linkage studies (Kurtz et al. 2005), tail-cuff blood pressure measurement in mice has considerable limitations because of the necessary physical restraint of mice and the limited time of measurement. Finally, in humans, polymorphism variance in LSD1 gene is associated with SSH. However, whether sex affects the mechanism(s) underlying the relationship between LSD1 function, aldosterone secretion and BP in humans is unclear. Sex-specific clinical studies are needed to address this question.

In conclusion, our data provide novel mechanistic insights into the development of SSH. By studying sex differences in a LSD1-knockdown mouse model, we observed aberrant aldosterone production in LSD1+/mice in both sexes: in males, the aberrant aldosterone production was associated with SSBP and increased microalbuminuria, suggesting that aldosterone plays an essential role in the pathogenesis of the SSBP. However, in females, no increase of BP was observed in association with the aberrant aldosterone production, suggesting intrinsic difference in the mechanisms underlying the hypertension in males vs females, with obvious clinical consequences. 


\section{Declaration of interest}

The authors declare that there is no conflict of interest that could be perceived as prejudicing the impartiality of the research reported.

\section{Funding}

The work was supported by the National Institute of Health National Heart, Lung, and Blood Institute Grants R01 HL114765 (G H W), R01 HL104032 (L H P), R01HL096518 ( R R), the American Heart Association: 14GRNT20500000 ( $\mathrm{L}$ H P) and by fellowship from the Ministry of Rural and Regional Development Malaysia (MARA) (C C).

\section{Acknowledgements}

The authors gratefully acknowledge the technical assistance of Paul Loutraris.

\section{References}

Abbate M, Benigni A, Bertani T \& Remuzzi G 1999 Nephrotoxicity of increased glomerular protein traffic. Nephrology Dialysis Transplantation 14 304-312. (https://doi.org/10.1093/ndt/14.2.304)

Baldoncini R, Desideri G, Bellini C, Valenti M, De Mattia G, Santucci A \& Ferri C 1999 High plasma renin activity is combined with elevated urinary albumin excretion in essential hypertensive patients. Kidney International 56 1499-1504. (https://doi.org/10.1046/j.15231755.1999.00672.x)

Barratt J \& Topham P 2007 Urine proteomics: the present and future of measuring urinary protein components in disease. Canadian Medical Association Journal 177 361-368. (https://doi.org/10.1503/ cmaj.061590)

Barrett Mueller K, Lu Q, Mohammad NN, Luu V, McCurley A, Williams GH, Adler GK, Karas RH \& Jaffe IZ 2014 Estrogen receptor inhibits mineralocorticoid receptor transcriptional regulatory function. Endocrinology 155 4461-4472. (https://doi.org/10.1210/ en.2014-1270)

Baudrand R, Pojoga LH, Romero JR \& Williams GH 2014 Aldosterone's mechanism of action: roles of lysine-specific demethylase 1, caveolin and striatin. Current Opinion in Nephrology and Hypertension 23 32-37. (https://doi.org/10.1097/01.mnh.0000436543.48391.e0)

Baudrand R, Pojoga LH, Vaidya A, Garza AE, Vohringer PA, Jeunemaitre X, Hopkins PN, Yao TM, Williams J, Adler GK, et al. 2015 Statin use and adrenal aldosterone production in hypertensive and diabetic subjects. Circulation 132 1825-1833. (https://doi. org/10.1161/CIRCULATIONAHA.115.016759)

Baudrand R, Guarda FJ, Fardella C, Hundemer G, Brown J, Williams G \& Vaidya A 2017 Continuum of renin-independent aldosteronism in normotension. Hypertension 69 950-956. (https://doi.org/10.1161/ HYPERTENSIONAHA.116.08952)

Bennesch MA, Segala G, Wider D \& Picard D 2016 LSD1 engages a corepressor complex for the activation of the estrogen receptor alpha by estrogen and cAMP. Nucleic Acids Research 44 8655-8670. (https:// doi.org/10.1093/nar/gkw522)

Bianchi S, Bigazzi R \& Campese VM 2005 Antagonists of aldosterone and proteinuria in patients with CKD: an uncontrolled pilot study. American Journal of Kidney Diseases 46 45-51. (https://doi. org/10.1053/j.ajkd.2005.03.007)

Braley LM, Menachery A \& Williams GH 1981 Angiotensin II's role in mediating angiotensin I- and tetradecapeptide-induced steroidogenesis by rat glomerulosa cells. Endocrinology 109 960-965. (https://doi.org/10.1210/endo-109-3-960)
Braley LM, Menachery AI, Yao T, Mortensen RM \& Williams GH 1996 Effect of progesterone on aldosterone secretion in rats. Endocrinology 137 4773-4778. (https://doi.org/10.1210/endo.137.11.8895346)

Brown JM, Robinson-Cohen C, Luque-Fernandez MA, Allison MA, Baudrand R, Ix JH, Kestenbaum B, de Boer IH \& Vaidya A 2017 The spectrum of subclinical primary aldosteronism and incident hypertension: a cohort study. Annals of Internal Medicine 167 630-641. (https://doi.org/10.7326/M17-0882)

Bubb KJ, Khambata RS \& Ahluwalia A 2012 Sexual dimorphism in rodent models of hypertension and atherosclerosis. British Journal of Pharmacology 167 298-312. (https://doi.org/10.1111/j.14765381.2012.02036.x)

Carvalho JJ, Baruzzi RG, Howard PF, Poulter N, Alpers MP, Franco LJ, Marcopito LF, Spooner VJ, Dyer AR, Elliott P, et al. 1989 Blood pressure in four remote populations in the INTERSALT Study. Hypertension 14 238-246. (https://doi.org/10.1161/01.HYP.14.3.238)

Cho HS, Suzuki T, Dohmae N, Hayami S, Unoki M, Yoshimatsu M, Toyokawa G, Takawa M, Chen T, Kurash JK, et al. 2011 Demethylation of RB regulator MYPT1 by histone demethylase LSD1 promotes cell cycle progression in cancer cells. Cancer Research 71 655-660. (https:// doi.org/10.1158/0008-5472.CAN-10-2446)

Chong C, Hamid A, Yao T, Garza AE, Pojoga LH, Adler GK, Romero JR \& Williams GH 2017 Regulation of aldosterone secretion by mineralocorticoid receptor-mediated signaling. Journal of Endocrinology 232 525-534. (https://doi.org/10.1530/JOE-16-0452)

Chuengsamarn S, Garza AE, Krug AW, Romero JR, Adler GK, Williams GH \& Pojoga LH 2013 Direct renin inhibition modulates insulin resistance in caveolin-1-deficient mice. Metabolism 62 275-281. (https://doi.org/10.1016/j.metabol.2012.07.013)

Coylewright M, Reckelhoff JF \& Ouyang P 2008 Menopause and hypertension: an age-old debate. Hypertension 51 952-959. (https:// doi.org/10.1161/HYPERTENSIONAHA.107.105742)

Danser AH, Derkx FH, Schalekamp MA, Hense HW, Riegger GA \& Schunkert H 1998 Determinants of interindividual variation of renin and prorenin concentrations: evidence for a sexual dimorphism of (pro)renin levels in humans. Journal of Hypertension 16 853-862. (https://doi.org/10.1097/00004872-199816060-00017)

Ehrhart-Bornstein M, Hinson JP, Bornstein SR, Scherbaum WA \& Vinson GP 1998 Intraadrenal interactions in the regulation of adrenocortical steroidogenesis. Endocrine Reviews 19 101-143. (https:// doi.org/10.1210/edrv.19.2.0326)

Epstein M 2001 Aldosterone as a mediator of progressive renal dysfunction: evolving perspectives. Internal Medicine 40 573-583. (https://doi.org/10.2169/internalmedicine.40.573)

Felicio LS, Nelson JF \& Finch CE 1984 Longitudinal studies of estrous cyclicity in aging C57BL/6J mice: II. Cessation of cyclicity and the duration of persistent vaginal cornification. Biology of Reproduction 31 446-453. (https://doi.org/10.1095/biolreprod31.3.446)

Franco V \& Oparil S 2006 Salt sensitivity, a determinant of blood pressure, cardiovascular disease and survival. Journal of the American College of Nutrition 25 247S-255S. (https://doi.org/10.1080/07315724 .2006.10719574)

Funder JW, Carey RM, Fardella C, Gomez-Sanchez CE, Mantero F, Stowasser M, Young WF Jr, Montori VM \& Endocrine S 2008 Case detection, diagnosis, and treatment of patients with primary aldosteronism: an endocrine society clinical practice guideline. Journal of Clinical Endocrinology and Metabolism 93 3266-3281. (https://doi. org/10.1210/jc.2008-0104)

Garcia-Bassets I, Kwon YS, Telese F, Prefontaine GG, Hutt KR, Cheng CS, Ju BG, Ohgi KA, Wang J, Escoubet-Lozach L, et al. 2007 Histone methylation-dependent mechanisms impose ligand dependency for gene activation by nuclear receptors. Cell 128 505-518. (https://doi. org/10.1016/j.cell.2006.12.038)

Garza AE, Rariy CM, Sun B, Williams JS, Lasky-Su J, Baudrand R, Yao T, Moize B, Hafiz WM, Romero JR, et al. 2015 Variants in striatin gene are associated with salt-sensitive blood pressure in mice https://joe.bioscientifica.com https://doi.org/10.1530/JOE-18-0247 (c) 2019 Society for Endocrinology Published by Bioscientifica Ltd. Printed in Great Britain 
and humans. Hypertension 65 211-217. (https://doi.org/10.1161/ HYPERTENSIONAHA.114.04233)

Gomez-Sanchez EP, Gomez-Sanchez CM, Plonczynski M \& GomezSanchez CE 2010 Aldosterone synthesis in the brain contributes to Dahl salt-sensitive rat hypertension. Experimental Physiology 95 120-130. (https://doi.org/10.1113/expphysiol.2009.048900)

Gould MM, Mohamed-Ali V, Goubet SA, Yudkin JS \& Haines AP 1993 Microalbuminuria: associations with height and sex in nondiabetic subjects. BMJ 306 240-242. (https://doi.org/10.1136/ bmj.306.6872.240)

Hamamoto R, Saloura V \& Nakamura Y 2015 Critical roles of non-histone protein lysine methylation in human tumorigenesis. Nature Reviews Cancer 15 110-124. (https://doi.org/10.1038/nrc3884)

Himmelmann A, Svensson A \& Hansson L 1994 Influence of sex on blood pressure and left ventricular mass in adolescents: the hypertension in pregnancy offspring study. Journal of Human Hypertension 8 485-490.

Hollenberg NK 2004 Aldosterone in the development and progression of renal injury. Kidney International 66 1-9. (https://doi.org/10.1111/ j.1523-1755.2004.00701.x)

Hostetter TH \& Ibrahim HN 2003 Aldosterone in chronic kidney and cardiac disease. Journal of the American Society of Nephrology $\mathbf{1 4}$ 2395-2401. (https://doi.org/10.1097/01.ASN.0000086472.65806.73)

Huang J, Sengupta R, Espejo AB, Lee MG, Dorsey JA, Richter M, Opravil S, Shiekhattar R, Bedford MT, Jenuwein T, et al. 2007 p53 is regulated by the lysine demethylase LSD1. Nature $\mathbf{4 4 9}$ 105-108. (https://doi. org/10.1038/nature06092)

Hundemer GL, Curhan GC, Yozamp N, Wang M \& Vaidya A 2018 Cardiometabolic outcomes and mortality in medically treated primary aldosteronism: a retrospective cohort study. Lancet Diabetes and Endocrinology 6 51-59. (https://doi.org/10.1016/S22138587(17)30367-4)

Kang AK \& Miller JA 2002 Effects of gender on the renin-angiotensin system, blood pressure, and renal function. Current Hypertension Reports 4 143-151. (https://doi.org/10.1007/s11906-002-0039-9)

Karatas A, Hegner B, de Windt LJ, Luft FC, Schubert C, Gross V, Akashi YJ, Gurgen D, Kintscher U, da Costa Goncalves AC, et al. 2008 Deoxycorticosterone acetate-salt mice exhibit blood pressureindependent sexual dimorphism. Hypertension 51 1177-1183. (https://doi.org/10.1161/HYPERTENSIONAHA.107.107938)

Kathiresan S, Larson MG, Benjamin EJ, Corey D, Murabito JM, Fox CS, Wilson PW, Rifai N, Meigs JB, Ricken G, et al. 2005 Clinical and genetic correlates of serum aldosterone in the community: the Framingham Heart Study. American Journal of Hypertension 18 657-665. (https://doi.org/10.1016/j.amjhyper.2004.12.005)

Katz FH, Romfh P, Zimmering PE \& Kelly WG 1972 Radioimmunoassay of plasma aldosterone: effect of sexual differences and increasing duration of upright posture. Steroids and Lipids Research 3 90-100.

Kontaki H \& Talianidis I 2010 Lysine methylation regulates E2F1-induced cell death. Molecular Cell 39 152-160. (https://doi.org/10.1016/j. molcel.2010.06.006)

Krug AW, Tille E, Sun B, Pojoga L, Williams J, Chamarthi B, Lichtman AH, Hopkins PN, Adler GK \& Williams GH 2013 Lysine-specific demethylase-1 modifies the age effect on blood pressure sensitivity to dietary salt intake. Age 35 1809-1820. (https://doi.org/10.1007/ s11357-012-9480-0)

Kurtz TW, Griffin KA, Bidani AK, Davisson RL, Hall JE \& Subcommittee of P \& Public Education of the American Heart A 2005 Recommendations for blood pressure measurement in humans and experimental animals. Part 2: blood pressure measurement in experimental animals: a statement for professionals from the subcommittee of professional and public education of the American Heart Association council on high blood pressure research. Hypertension 45 299-310. (https://doi.org/10.1161/01. HYP.0000150857.39919.cb)

Lumbers ER 1999 Angiotensin and aldosterone. Regulatory Peptides 80 91-100. (https://doi.org/10.1016/S0167-0115(99)00026-9)
Manrique C, DeMarco VG, Aroor AR, Mugerfeld I, Garro M, Habibi J, Hayden MR \& Sowers JR 2013 Obesity and insulin resistance induce early development of diastolic dysfunction in young female mice fed a Western diet. Endocrinology 154 3632-3642. (https://doi. org/10.1210/en.2013-1256)

Masineni SN, Chander PN, Singh GD, Powers CA \& Stier CT Jr 2005 Male gender and not the severity of hypertension is associated with end-organ damage in aged stroke-prone spontaneously hypertensive rats. American Journal of Hypertension 18 878-884. (https://doi. org/10.1016/j.amjhyper.2004.12.014)

Metzger E, Wissmann M, Yin N, Muller JM, Schneider R, Peters AH, Gunther T, Buettner R \& Schule R 2005 LSD1 demethylates repressive histone marks to promote androgen-receptor-dependent transcription. Nature 437 436-439. (https://doi.org/10.1038/ nature04020)

Miller JA, Anacta LA \& Cattran DC 1999 Impact of gender on the renal response to angiotensin II. Kidney International 55 278-285. (https:// doi.org/10.1046/j.1523-1755.1999.00260.x)

Nelson JF, Felicio LS, Randall PK, Sims C \& Finch CE 1982 A longitudinal study of estrous cyclicity in aging C57BL/6J mice: I. Cycle frequency, length and vaginal cytology. Biology of Reproduction 27 327-339. (https://doi.org/10.1095/biolreprod27.2.327)

Nitta K, Uchida K \& Nihei H 2004 Spironolactone and angiotensin receptor blocker in nondiabetic renal diseases. American Journal of Medicine 117 444-445. (https://doi.org/10.1016/j. amjmed.2004.04.020)

Oestreicher EM, Guo C, Seely EW, Kikuchi T, Martinez-Vasquez D, Jonasson L, Yao T, Burr D, Mayoral S, Roubsanthisuk W, et al. 2006 Estradiol increases proteinuria and angiotensin II type 1 receptor in kidneys of rats receiving L-NAME and angiotensin II. Kidney International 70 1759-1768. (https://doi.org/10.1038/sj.ki.5001897)

Ostchega Y, Yoon SS, Hughes J \& Louis T 2008 Hypertension awareness, treatment, and control - continued disparities in adults: United States, 2005-2006. NCHS Data Brief 1-8.

Ouchi Y, Share L, Crofton JT, Iitake K \& Brooks DP 1987 Sex difference in the development of deoxycorticosterone-salt hypertension in the rat. Hypertension 9 172-177. (https://doi.org/10.1161/01. HYP.9.2.172)

Pimenta E, Gaddam KK, Pratt-Ubunama MN, Nishizaka MK, Aban I, Oparil S \& Calhoun DA 2008 Relation of dietary salt and aldosterone to urinary protein excretion in subjects with resistant hypertension. Hypertension 51 339-344. (https://doi.org/10.1161/ HYPERTENSIONAHA.107.100701)

Pojoga LH, Romero JR, Yao TM, Loutraris P, Ricchiuti V, Coutinho P, Guo C, Lapointe N, Stone JR, Adler GK, et al. 2010 Caveolin-1 ablation reduces the adverse cardiovascular effects of N-omeganitro-L-arginine methyl ester and angiotensin II. Endocrinology 151 1236-1246. (https://doi.org/10.1210/en.2009-0514)

Pojoga LH, Williams JS, Yao TM, Kumar A, Raffetto JD, do Nascimento GR, Reslan OM, Adler GK, Williams GH, Shi Y, et al. 2011 Histone demethylase LSD1 deficiency during high-salt diet is associated with enhanced vascular contraction, altered NO-cGMP relaxation pathway, and hypertension. American Journal of PhysiologyHeart and Circulatory Physiology 301 H1862-H1871. (https://doi. org/10.1152/ajpheart.00513.2011)

Pojoga LH, Yao TM, Opsasnick LA, Garza AE, Reslan OM, Adler GK, Williams GH \& Khalil RA 2014 Dissociation of hyperglycemia from altered vascular contraction and relaxation mechanisms in caveolin-1 null mice. Journal of Pharmacology and Experimental Therapeutics $\mathbf{3 4 8}$ 260-270. (https://doi.org/10.1124/jpet.113.209189)

Pojoga LH, Yao TM, Opsasnick LA, Siddiqui WT, Reslan OM, Adler GK, Williams GH \& Khalil RA 2015 Cooperative role of mineralocorticoid receptor and caveolin-1 in regulating the vascular response to low nitric oxide-high angiotensin ii-induced cardiovascular injury. Journal of Pharmacology and Experimental Therapeutics 355 32-47. (https://doi. org/10.1124/jpet.115.226043) 
Rayner B 2006 Importance of modulating the renin-angiotensin system in preventing renal complications of hypertension. Saudi Journal of Kidney Disease and Transplantation 17 469-480.

Reckelhoff JF 2001 Gender differences in the regulation of blood pressure. Hypertension 37 1199-1208. (https://doi.org/10.1161/01. HYP.37.5.1199)

Reckelhoff JF \& Maric C 2010 Sex and gender differences in cardiovascular-renal physiology and pathophysiology. Steroids $\mathbf{7 5}$ 745-746. (https://doi.org/10.1016/j.steroids.2010.05.020)

Ricchiuti V, Lapointe N, Pojoga L, Yao T, Tran L, Williams GH \& Adler GK 2011 Dietary sodium intake regulates angiotensin II type 1, mineralocorticoid receptor, and associated signaling proteins in heart. Journal of Endocrinology 211 47-54. (https://doi.org/10.1530/JOE-100458)

Rodriguez-Iturbe B \& Vaziri ND 2007 Salt-sensitive hypertension - update on novel findings. Nephrology Dialysis Transplantation 22 992-995. (https://doi.org/10.1093/ndt/gfl757)

Sandberg K \& Ji H 2003 Sex and the renin angiotensin system: implications for gender differences in the progression of kidney disease. Advances in Renal Replacement Therapy 10 15-23. (https://doi. org/10.1053/jarr.2003.50006)

Sato A, Hayashi K, Naruse M \& Saruta T 2003 Effectiveness of aldosterone blockade in patients with diabetic nephropathy. Hypertension 41 64-68. (https://doi.org/10.1161/01.HYP.0000044937.95080.E9)

Schrader J, Luders S, Kulschewski A, Hammersen F, Zuchner C, Venneklaas U, Schrandt G, Schnieders M, Rangoonwala B, Berger J, et al. 2006 Microalbuminuria and tubular proteinuria as risk predictors of cardiovascular morbidity and mortality in essential hypertension: final results of a prospective long-term study (MARPLE Study)*. Journal of Hypertension 24 541-548. (https://doi. org/10.1097/01.hjh.0000209991.48928.c4)

Schunkert H, Danser AH, Hense HW, Derkx FH, Kurzinger S \& Riegger GA 1997 Effects of estrogen replacement therapy on the reninangiotensin system in postmenopausal women. Circulation 95 39-45. (https://doi.org/10.1161/01.CIR.95.1.39)

Shi Y, Lan F, Matson C, Mulligan P, Whetstine JR, Cole PA, Casero RA \& Shi Y 2004 Histone demethylation mediated by the nuclear amine oxidase homolog LSD1. Cell 119 941-953. (https://doi.org/10.1016/j. cell.2004.12.012)

Shukri MZ, Tan JW, Manosroi W, Pojoga LH, Rivera A, Williams JS, Seely EW, Adler GK, Jaffe IZ, Karas RH, et al. 2018 Biological sex modulates the adrenal and blood pressure responses to angiotensin II. Hypertension 71 1083-1090. (https://doi.org/10.1161/ HYPERTENSIONAHA.117.11087)

Simon PH, Sylvestre MP, Tremblay J \& Hamet P 2016 Key Considerations and Methods in the Study of Gene-Environment Interactions. American Journal of Hypertension 29 891-899. (https://doi.org/10.1093/ ajh/hpw021)

Spat A \& Hunyady L 2004 Control of aldosterone secretion: a model for convergence in cellular signaling pathways. Physiological Reviews 84 489-539. (https://doi.org/10.1152/physrev.00030.2003)

Spyroglou A, Sabrautzki S, Rathkolb B, Bozoglu T, Hrabe de Angelis M, Reincke M, Bidlingmaier M \& Beuschlein F 2012 Gender-, strain-, and inheritance-dependent variation in aldosterone secretion in mice. Journal of Endocrinology 215 375-381. (https://doi.org/10.1530/JOE12-0429)

Stier CT Jr, Chander PN, Rosenfeld L \& Powers CA 2003 Estrogen promotes microvascular pathology in female stroke-prone spontaneously hypertensive rats. American Journal of PhysiologyEndocrinology and Metabolism 285 E232-E239. (https://doi. org/10.1152/ajpendo.00029.2003)

Wang J, Hevi S, Kurash JK, Lei H, Gay F, Bajko J, Su H, Sun W, Chang H, $\mathrm{Xu}$ G, et al. 2009 The lysine demethylase LSD1 (KDM1) is required for maintenance of global DNA methylation. Nature Genetics 41 125-129. (https://doi.org/10.1038/ng.268)

Watson LE, Jewell C, Song J \& Dostal DE 2013 Echocardiographic effects of eplerenone and aldosterone in hypertensive rats. Frontiers in Bioscience 5 922-927. (https://doi.org/10.2741/E671)

Williams GH 2005 Aldosterone biosynthesis, regulation, and classical mechanism of action. Heart Failure Reviews 10 7-13. (https://doi. org/10.1007/s10741-005-2343-3)

Williams GH \& Hollenberg NK 1991 Functional derangements in the regulation of aldosterone secretion in hypertension. Hypertension 18 III143-III149.

Williams JS, Chamarthi B, Goodarzi MO, Pojoga LH, Sun B, Garza AE, Raby BA, Adler GK, Hopkins PN, Brown NJ, et al. 2012 Lysine-specific demethylase 1: an epigenetic regulator of salt-sensitive hypertension. American Journal of Hypertension 25 812-817. (https:/doi.org/10.1038/ ajh.2012.43)

Yong LC, Kuller LH, Rutan G \& Bunker C 1993 Longitudinal study of blood pressure: changes and determinants from adolescence to middle age. The Dormont High School follow-up study, 1957-1963 to 1989-1990. American Journal of Epidemiology 138 973-983. (https:// doi.org/10.1093/oxfordjournals.aje.a116817)

Received in final form 15 October 2018

Accepted 26 October 2018

Accepted Preprint published online 1 November 2018 (c) 2019 Society for Endocrinology Published by Bioscientifica Ltd. Printed in Great Britain 